Volume 10, No.1, January - February 2021

International Journal of Advanced Trends in Computer Science and Engineering

Available Online at http://www.warse.org/IJATCSE/static/pdf/file/ijatcse081012021.pdf

https://doi.org/10.30534/ijatcse/2021/081012021

\title{
Risk Management in the Design of the Organization and Technology for the Construction of Buried Structures in Conditions of Compacted Development
}

\author{
Oleksandr Galinsky ${ }^{1}$, Olena Emelianova ${ }^{2}$, Viktoriya Tytok $^{3}$ \\ ${ }^{1}$ Department of Construction Organization and Management, Kyiv National University of Construction and \\ Architecture, Kyiv, Ukraine, agalin@ukr.net \\ ${ }^{2}$ Department of Construction Organization and Management, Kyiv National University of Construction and \\ Architecture, Kyiv, Ukraine, mkelena1@ukr.net \\ ${ }^{3}$ Department of Construction Economics, Kyiv National University of Construction and Architecture, Kyiv, \\ Ukraine, victoriatytok@gmail.com
}

\begin{abstract}
The article substantiates the feasibility of developing and implementing a risk management plan for the implementation of construction projects in the conditions of compacted construction on the basis of risk identification at the stages of development of projects of organization and construction technology. The risk management algorithm is given. Design of construction of structures in conditions of compacted development usually requires consideration of many factors (risks) that affect the safety and quality of construction, but, as a rule, the most significant risks arise in the construction of the deepened part of the structure - "zero cycle". With this in mind, a Risk Management Plan for the construction of the "zero cycle" is proposed and emphasis is placed on the need to develop a strategy for the protection of the surrounding area and buildings. The conditions for achieving optimal efficiency of the Risk Management Plan are determined.
\end{abstract}

Key words : risk analysis, residual risk, compacted buildings, risk management plan.

\section{INTRODUCTION}

Management of risks [1, 3-5], which arise when designing construction organization and technology $[2,6,7]$ and performing construction works, has to be carried out by a project team (investor, customer, consulting engineer, planner, contractor) and focus on the key issues of the project that are likely to be affected by significant risks, or that promise maximum savings in terms of time and costs due to application of appropriate engineering techniques or use of financial facilities (loans, insurance).

Early risk identification facilitates proactive project improvement, when the problems are mitigated as soon as they are detected, which process differs fundamentally from the traditional approach to construction, when critical issues are dealt with as they manifest themselves.

Risk analysis and risk management in construction, especially in restrained urban conditions, become more and more important, taking into account the ever growing needs of population, investors, creditors and insurance companies related to construction safety, ecological, social and economic stability [8-12].

\section{MAIN MATERIAL}

Risk analysis and risk management are applied for all stages of the project. The risks can be categorized into those that are associated with the concept development and design phase, construction phase, operation phase, as well as decommissioning phase.

The approach to risk management consists in identifying and compiling a list of potential hazards associated with construction organization and technology, determining probability of occurrence for each hazard and establishing its severity factor.

The next step lies in defining measures designed to reduce probability of occurrence of an event and mitigate its severity factor (the so called "risk mitigation measures").

Risk reduction includes:

- active procedures - avoiding or reducing the hazard;

- passive procedures - selection of specific measures to minimize or mitigate the adverse consequences.

All risk categories must be strictly pre-distributed among specific project participants - risk owners, taking into account their special ability to manage different risk sources.

First of all, it is necessary to consider three main risk management strategies:

- to preserve the risk; 
Oleksandr Galinsky et al., International Journal of Advanced Trends in Computer Science and Engineering, 10(1), January - February 2021, 54 60

- to transfer the risk by assigning it to one of the key contracting agents;

- to transfer the risk to professional agencies which are specialized in risk management (insurance companies).

The main sources of risks that have to be taken into consideration when developing project design documentation and executing construction works are:

\section{GEOLOGY AND HYDROGEOLOGY OF THE} CONSTRUCTION SITE - DUE TO:

- limited research at the design and / or construction stage (limited time and budget, lack of access to the site, etc.);

- inappropriate tests conducted at the construction site and / or in the laboratory;

- insufficient understanding of soil properties;

- insufficient understanding of specific soil deformation mechanisms;

- insufficient understanding of how the soil foundation of the nearby buildings will react to excavation works in the foundation pit;

- lack of systematic research and monitoring during construction.

\section{DESIGN - DUE TO:}

- a designer lacking the required experience;

- inadequate analysis of constructability of buildings and structures;

- insufficient flexibility of the building's structure for adaptation to the existing construction site conditions;

- improper choice of construction methods, taking into account the entire range of the specific construction site conditions;

- absence of the established limit values of the parameters being controlled;

- absence of or drawbacks of the monitoring project related to determination of frequency of the corresponding parameter measurements;

- absence of or non-exhaustive analysis of potential risk scenarios;

- inadequate method of calculations, evaluation and forecasting of possible losses resulting from the impact of the existing buildings during construction, including restrained urban conditions;

- absence of or drawbacks of developing (establishing) counter measures;

- absence of or drawbacks of developing (establishing) criteria - alarm criteria for counter measures.

\section{CONSTRUCTION - DUE TO:}

- a contractor lacking the required experience;

- unqualified personnel;
- improper choice of construction techniques, machines, mechanisms, equipment;

- insufficient efficiency of the key technological machinery;

- absence of or inadequate project design documentation taking into account all existing conditions of a specific construction site;

- violation of building practices or absence of operation flow charts;

- works execution without performing a set of pre-construction activities;

- absence of quality management system, occupational health and safety management, environmental management;

- absence of construction monitoring system;

-poor logistics.

\section{RISK MANAGEMENT PLAN}

Risk management plan is a reliable and transparent procedure for efficient risk identification and joining, as well as dealing with the related issues.

The purpose of introduction of the risk management plan into the project is to effectively manage risks and reduce them to acceptable levels.

The risk management plan is based upon four main principles:

1. Risk identification:

- accessibility of information concerning the risk to the risk owner, in accordance with both the degree of indetermination and the degree of risk acceptability;

- risk registration - compilation of the comprehensive list of the identified potential hazards and the related initial risks which can be encountered at any stage of the project.

2. Risk assessment:

- establishment of the potential cause of the identified hazard;

- assessment of hazard probability;

- assessment of the impact the hazard might have on the project.

Preliminary assessment of the impact the risks might have on the project (assessment of sensitivity of the project to different types of risks) is conducted making use of:

- efficient methods of quantitative evaluation (e.g., engineering evaluations) [13];

- quantitative methods, for example, probabilistic analysis, which are used to determine both risk occurrence probability (P) and impact of the risk on the project (I) from the point of view of safety, time and costs (more reliable assessment) $[14,15]$.

The priority is given to the identified risks. Special attention is paid to unacceptable risks and those risks that will 
Oleksandr Galinsky et al., International Journal of Advanced Trends in Computer Science and Engineering, 10(1), January - February 2021, 54 60

have to be taken into account during subsequent stages of the project.

\section{Risk responses:}

- compilation of a list of risk responses designed to mitigate and reduce the initial risk, including:

- changes in the design of the building under construction;

- changes in organization (construction organization project) and/or construction technology (work execution project) [16];

- changes in managing execution of operating processes [17];

- substitution of machines, mechanisms, equipment, taking into consideration their efficiency, reliability and safety in use;

- improvement of project staffing and logistical support of construction;

- risk re-assessment for quantitative evaluation of the residual risk, taking into account the fact that after implementation of risk mitigation measures responsibility for the residual risk management can undergo changes;

- additional residual risk reduction;

- submission of information concerning risk responses on a regular basis.

\section{Risk monitoring}

Risks are monitored with the established frequency of obtaining values of the key parameters of potential risks in accordance with the developed monitoring project.

During risk monitoring the key parameters are checked risk indicators vs limit values of technical and organizational parameters of efficient construction management, including:

- monitoring of quality parameters with regard to materials, manufactured articles, structures;

- monitoring of construction organization parameters and technological processes [18];

- monitoring of work execution terms;

- monitoring of requirements pertaining to:

- fire safety;

- safety of personnel;

- environmental impact;

- energy conservation.

Based upon the results of monitoring and determination of risk parameters, which exceed limit values and are indications of the fact that some extremely dangerous situations exist, the corresponding counter measures developed at the design stage must be launched into action.

Launching of the risk management plan ensures timely detection and identification of potential problems; the plan has to be incorporated into the project from the concept design stage to operation stage covering each individual stage:

- engineering-geological survey, hydrogeological studies;

- research and development;

- development of engineering design documentation;
- development of process engineering documents;

- development of operational documentation;

- construction;

- construction support;

- operation.

Risk management plan has to be viewed as a dynamic process that needs to be followed up, updated, integrated and expanded across the entire project as presented in the Figure 1.

Timely and systematic updating of the risk register is one of the important pre-requisites for successful implementation of the project.

Introduction of the risk management plan implies involvement of all interested parties:

- investor (owner, customer);

- project manager (senior executive);

- consulting engineer;

- planner (architect, engineer);

- expert;

- contractor;

- supervisor (technical supervision, field supervision, state supervision).

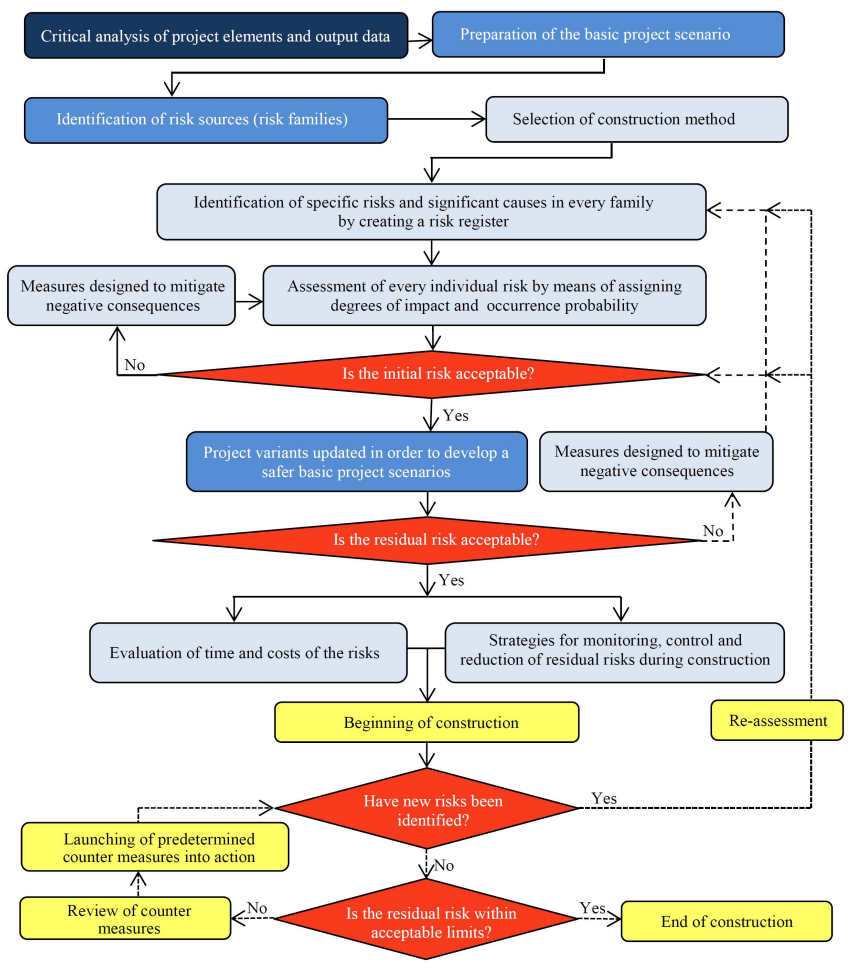

Figure 1: Risk management algorithm [8]

In reality, not all risks associated with construction can be completely eliminated or mitigated.

Risk management plan is a dynamic process taking place throughout the project's life cycle:

- initial risks have to be constantly updated; 
Oleksandr Galinsky et al., International Journal of Advanced Trends in Computer Science and Engineering, 10(1), January - February 2021, 54 60

- specific strategies for managing significant (known) residual risks are developed and put into action;

- residual risks are reviewed on a regular basis.

Customer and project manager must realize that certain risk for the Customer remains. This "residual risk" must be taken into consideration when the customer evaluates time and costs of construction.

A risk can be managed, minimized, shared, transferred or simply accepted, but it cannot be ignored.

\section{IDENTIFICATION OF INITIAL RISKS - RISK REGISTER UTILIZATION}

Phase 1. Analysis of output data and information for development of the construction project, including construction organization project, by a group of experts which is set up depending on complexity of the project:

- analysis and study of information which can affect the choice of construction concepts and techniques:

- published data concerning local geological and hydrogeological conditions, results of research conducted by experienced geologists and hydrogeologists;

- engineering networks in the vicinity of the construction site;

- buildings and other structures located within the area affected by the construction project;

- transport infrastructure, etc.;

- critical review of experience obtained during implementation of similar construction projects and risks which occurred at the time;

- consultations with potential Contractors and suppliers of specialized equipment;

- discussions on possible methods of construction, as well as a possibility of utilizing standard solutions.

Phase 2. Identification of associated risks (compilation of risk register) taking into account previous experience.

Structuring the Risk register, including:

- types (families) of hazards, specifying hazards and their causes in each of them as presented in the Table 1;

- quantitative evaluation of probability and impact of hazards - risks;

- determination of unacceptable initial risks;

- setting up a specific strategy for reduction of each initial risk (mitigation measures);

- quantitative evaluation of residual risks by re-assessing them with a provision that the mitigation methods have been implemented.

For each type (family) the list of significant risks can be compiled by means of holding talks with the key PROJECT PARTICIPANTS and/or the PROJECT TEAM brain-storming.
Table 1: Types (families) of risks are to be studied in two parallel contexts:

\begin{tabular}{|l|l|}
\hline - output data for design & $\begin{array}{l}\text { - methods of construction in } \\
\text { operations related to: }\end{array}$ \\
$\begin{array}{l}\text { relation to: } \\
\text { - geology, hydro-construction activities; }\end{array}$ \\
$\begin{array}{ll}\text { geological equipment; } & \text { - personnel qualifications; } \\
\text { - operation of the existing } & \text { - technological processes; } \\
\text { engineering networks; } & \text { - machines, mechanisms, } \\
\text { - buildings and structures } & \text { equipment; } \\
\text { within the construction project } & \text { - logistics, etc. } \\
\text { area; } & \\
\text { - environmental conditions; } & \\
\text { - transport infrastructure, etc. }\end{array}$
\end{tabular}

Phase 3. Final results of the initial risk analysis are used for the following purposes:

- to introduce the necessary corrections into the basic design scenarios;

- to select the best construction method;

- to develop a plan of additional site survey;

- to reduce the number of indeterminations;

- to determine the most suitable "mitigation measures";

- to determine the best possible "counter measures".

Phase 4. Designing risk identification scenarios

- The planner must have a possibility to manage project risks related to geology, hydrogeology, organization and construction technology, as well as all physical and ecological impacts, from conceptual design to further construction supervision.

- Following creation of the basic (reference) design, for which the risk sources have been properly specified, a sequential method for risk identification during the design stage is developed.

\section{IDENTIFICATION OF INITIAL RISKS - RISK REGISTER UTILIZATION (EXAMPLIFIED BY THE RISK MANAGEMENT PLAN FOR THE CONSTRUCTION PROJECT IN RESTRAINED URBAN CONDITIONS)}

\section{RESTRAINED URBAN CONDITIONS:}

- erection of a building in close proximity to the existing buildings, structures, engineering networks or land improvement facilities;

- risk of negative technogenic impact the construction project might have on nearby buildings or land improvement facilities;

- risk of negative impact the construction project might have on foundations and supporting structures of nearby buildings or engineering networks;

- risk of deterioration of human habitat - the place where people live, work or stay temporarily close to the construction site area.

Generally, construction in restricted urban conditions requires the use of numerous different design components, but 
usually the most significant risks arise during substructure and utility communications construction (the so called "zero cycle") as presented in the Figure 2.

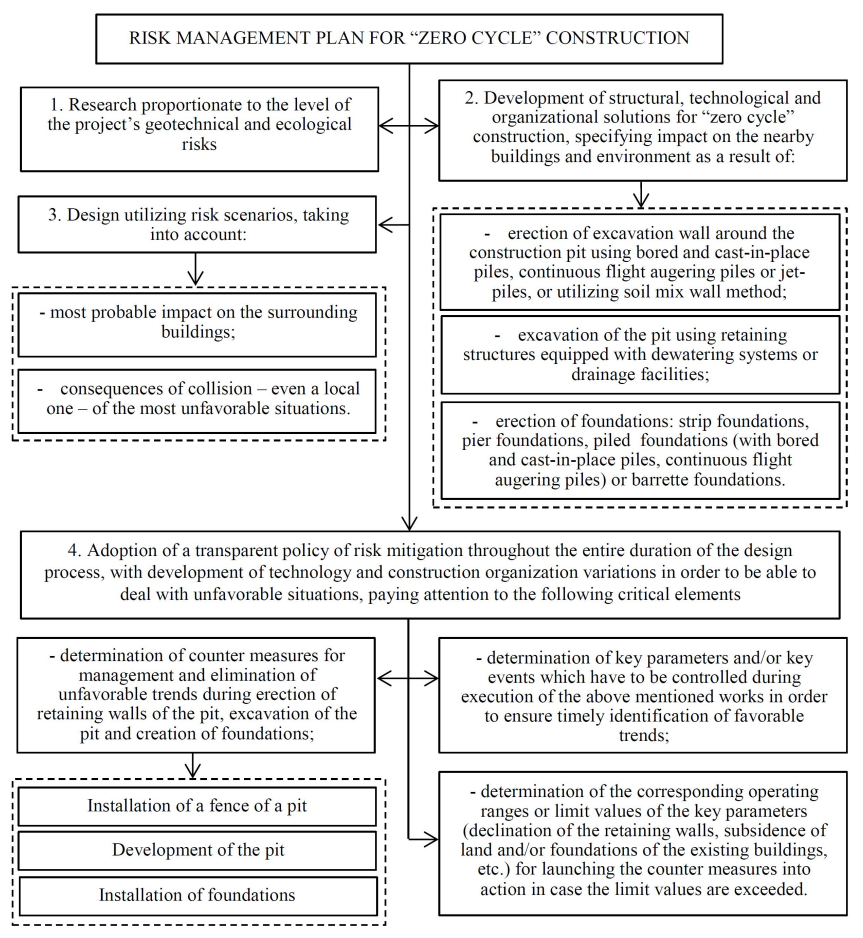

Figure 2: Risk management plan for "zero cycle" construction

When selecting construction solutions for substructures and methods of their erection in restricted urban conditions, it is necessary to take into consideration the following conditions:

- location and construction solutions used in the nearby buildings and facilities;

- nature and zone of mutual influence of the building under construction and the nearby buildings and structures;

- forecasts with regard to environmental and technogenic conditions at the construction site;

- inadmissible damaging of foundations and supporting structures of the nearby buildings;

- inadmissibility of reducing operating properties of the nearby buildings and structures;

- inadmissibility of deterioration of environmental, geological and hydrogeological situation as a result of erection of substructures.

Design of pits and foundations for construction in restricted urban conditions must be substantiated by calculations pertaining to protection of the existing buildings and nearby territory from negative impact of construction operations.

The project must include the sequence of operations for substructure and utility communications construction ("zero cycle"), which is designed to protect the existing buildings and facilities.

Special attention must be paid to calculations of durability of the walls of deep pits, which in restricted urban conditions are usually made of piles (located in a row or using a criss-cross pattern) or applying the soil mix wall method with subsequent tier lining, making use of anchors, temporary sprung structures, counterforces or slabs (top-down construction method, or sequence).

Calculations of durability of the pit walls must necessarily take into account two periods of time:

1. Period of time when the pit is being excavated and not all tier fixtures are installed yet as presented in the Figure 3.

2. Period of time when the pit is in "operation", with all tier fixtures installed in accordance with the design as presented in the Figure 4.

Usually the most dangerous period is the time when the pit is being excavated, during which period of time the loads acting on the retaining walls are not transmitted to all designated expanding elements.

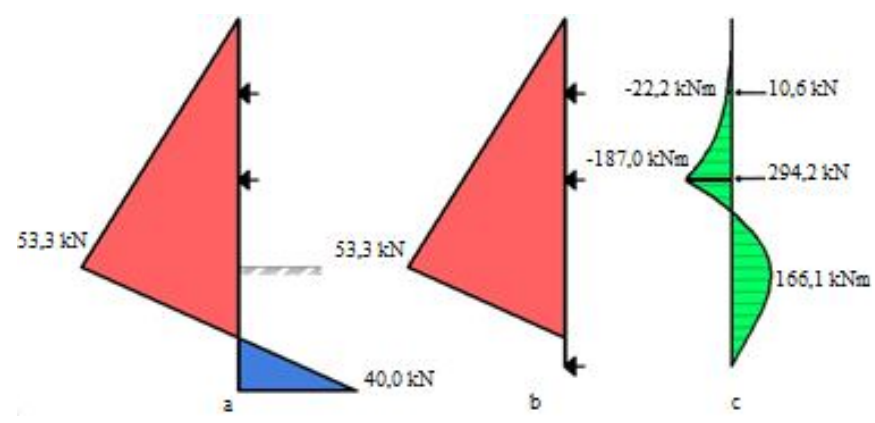

Figure 3: Resultant loads and bending moments acting on the retaining walls during pit excavation: (a) resultant load acting on the retaining wall; (b) structural diagram; (c) bending moments and support resistance

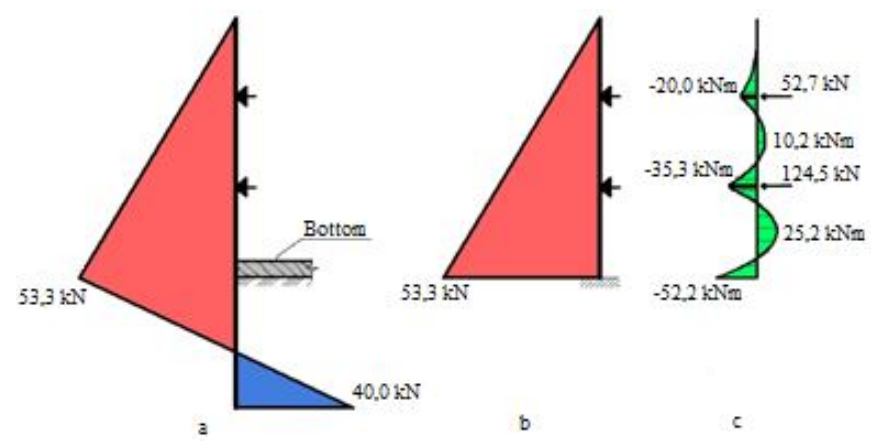

Figure 4: Resultant loads and bending moments acting on the retaining walls during "operation" of the pit: (a) resultant load acting on the retaining wall; (b) structural diagram; (c) bending moments and support resistance (significantly reduced as compared with the time when the pit was being excavated)

When designing and implementing a construction project in restricted urban conditions, it is necessary:

To develop a strategy for protection of buildings that requires the following actions: 
- to inspect and determine technical condition of all identified buildings and structures influenced by construction operations prior to the start of the work;

- to perform analysis and study attitude of inhabitants of each identified building towards the new construction project;

- to classify all identified buildings into different risk categories;

- to use the inspection results to assess durability of the buildings and potential damage;

- to determine which buildings pose a danger and which structures require protection; to develop the corresponding organizational, structural and technological solutions;

- to establish a dedicated system for classification of damages in relation to the project;

- to determine which buildings require inspection and special monitoring during construction;

- to develop an efficient monitoring plan;

- to carry out inspections after construction is finished, regardless of whether the buildings were affected or not, and whether any damage was inflicted or not;

- to file and maintain all data for future use.

During implementation of the project in restricted urban conditions, within the framework of the risk management plan the consulting engineer must have a possibility to monitor the construction process, to have feedback from the customer, planner and contractor in order to quickly and efficiently introduce corrective changes in structures and technological processes in case the construction conditions are changed in order to ensure safe operations, time-saving and cost reduction.

\section{CONCLUSION}

Optimum efficiency of the risk management plan is achieved when development of construction organization and technology is supported by availability of qualified and skilled personnel, as well as creation and implementation of procedures designed to take on all challenges of a construction project, to manage basic technological processes and to deal with all potential risks.

\section{REFERENCES}

1. IEC 31010:2019 Risk management - Risk assessment techniques.

2. DBN A.3.1-5:2016 Organizatsiia budivelnogo vyrobnytstva. [State building codes Ukraine DBN A.3.1-5:2016. Organization of construction production]. Kyiv, Minregion Ukrainy Publ., 2016, 46 p. Available at: http://online.budstandart.com/ua/catalog/doc-page.html ?id_doc=64312. (in Ukrainian).

3. V. Tkachenko, M. Klymchuk, I. Tkachenko and T. Ilina. Risk management system references in construction,
Research Papers in Economics and Finance. 4 (1) 2020, pp. 21-30. https://doi.org/10.18559/ref.2020.1.2

4. A. L. Meroño-Cerdán, C. López-Nicolás and F. J. Molina-Castill, Risk aversion, innovation and performance in family firms, Economics of Innovation and New Technology, Vol. 27, Issue 2, 2018, pp. 189-203, DOI: 10.1080/10438599.2017.1325569.

5. J. K. Visser and H. T. Malan. Identification of risk associated with process automation systems, International Journal of Economics and Management Engineering, Vol. 13, No 7, 2019, pp. 1044-1051. doi.org/10.5281/zenodo.3455555.

6. S. P. Stetsenko, V. V. Tytok, O. M. Emelianova, O. Yu. Bielienkova and T. Yu. Tsyfra. Management of Adaptation of Organizational and Economic Mechanisms of Construction to Increasing Impact of Digital Technologies on the National Economy, Journal of Reviews on Global Economic, 2020, № 9, pp. 149-164.

DOI: https://doi.org/10.6000/1929-7092.2020.09.15

7. T. Hartmann, H. van Meerveld, N. Vossebeld and A. Adriaanse. Aligning building information model tools and construction management methods, Automation in Construction, Vol. 22, 2012, pp. 605-613, https://doi.org/10.1016/j.autcon.2011.12.011.

8. P. Grasso and L. Soldo. Risk analysis-driven design in tunnelling: the state-of-the-art, learnt from past experiences, and horizon for future development, Innovative Infrastructure Solutions, Vol. 2, Issue 1, 49, 2017. https://doi.org/10.1007/s41062-017-0087-2.

9. A. Rostami, J. Sommerville, I.L. Wong and C. Lee. Risk management implementation in small and medium enterprises in the UK construction industry, Engineering, Construction and Architectural Management, Vol. 22 No. 1, 2015, pp. 91-107. https://doi.org/10.1108/ECAM-04-2014-0057

10. L. A. Gordon, M. P. Loeb and C.-Y. Tseng. Enterprise risk management and firm performance: A contingency perspective, Journal of Accounting and Public Policy, Vol. 28, Issue 4, 2009, pp. 301-327, https://doi.org/10.1016/j.jaccpubpol.2009.06.006.

11. X. Zhao, B.-G. Hwang, M.ASCE, S. P. Low and P. Wu. Reducing Hindrances to Enterprise Risk Management Implementation in Construction Firms, Journal of Construction Engineering and Management, Vol. 141, Issue 3, March 2015. https://doi.org/10.1061/(ASCE)CO.1943-7862.0000945

12. P. Szymanski. Risk management in construction projects, Procedia Engineering, Vol. 208, 2017, pp. 174-182. https://doi.org/10.1016/j.proeng.2017.11.036.

13. O. M. Galinsky, O. S. Molodid, N. V. Sharikina and R. O. Plokhuta. Research of technologies for restoration of the concrete protective layer of reinforced concrete constructions during the reconstruction of the buildings and structures, IOP Conference Series: Materials Science and Engineering, Vol. 907, Innovative Technology in Architecture and Design (ITAD 2020) 
21-22 May 2020, Kharkiv, Ukraine. DOI: 10.1088/1757-899X/907/1/012056

14. T. Honcharenko, Y. Chupryna, I. Ivakhnenko, M. Zinchenco and T. Tsyfra. Reengineering of the Construction Companies Based on BIM-technology, International Journal of Emerging Trends in Engineering Research, 8(8), August 2020, pp. 4166-4172. https://doi.org/10.30534/ijeter/2020/22882020

15. D. Chernyshev, D. Ryzhakov, O. Dikiy, O. Khomenko and S.Petrukha. Innovative Technology for Management Tools of Commercial Real Estate in Construction, International Journal on Emerging Trends in Engineering Research, 8(9), September 2020, pp. 4967-4973, https://doi.org/10.30534/ijeter/2020/13892020

16. D. Ryzhakov, O. Dikiy, M. Druzhynin, H. Petrenko and $\mathrm{T}$. Savchuk. Innovative tools for management the lifecycle of strategic objectives of the enterprise-stakeholder in construction, International Journal on Emerging Trends in Engineering Research, 8(8), 2020, pp. 4526-4532, https://doi.org/10.30534/ijeter/2020/78882020

17. A. G. Myasnikov. Information and logical modeling in construction, International Journal of Advanced Trends in Computer Science and Engineering, 9(1), January-February 2020, pp. 304-307, https://doi.org/10.30534/ijatcse/2020/46912020

18. I. L. Fedun, I. V. Novikova, I. L.Vildman, M. M. Klymchuk and M. O. Goryn. Concept of Innovative Marketing in Management of Enterprise, Journal of Advanced Research in Dynamical and Control Systems, Vol. 12, 07-Special Issue, 2020, pp. 352-358. DOI: $10.5373 / \mathrm{JARDCS} / \mathrm{V} 12 \mathrm{SP} 7 / 20202116$ 